\title{
A novel Mn(II) oxalato-bridged 2D coordination polymer: synthesis, crystal structure, spectroscopic, thermal and magnetic properties
}

\author{
HIBA SEHIMI ${ }^{\mathrm{a}, \mathrm{b}, *}$ (D) and MOHAMED FAOUZI ZID ${ }^{\mathrm{a}}$ \\ a Laboratoire de matériaux, cristallochimie et thermodynamique appliquée, Faculté des Sciences de Tunis, \\ Université de Tunis El Manar, LR15ES01, El Manar II, 2092 Tunis, Tunisia \\ ${ }^{\mathrm{b}}$ Faculté des Sciences de Gabès, Université de Gabès, Campus Universitaire, Cité Erriadh Zrig, 6072 Gabès, \\ Tunisia \\ E-mail: hiba.shimi@fst.utm.tn
}

MS received 22 November 2017; revised 18 January 2018; accepted 29 January 2018; published online 28 February 2018

\begin{abstract}
Besides the fact that direct synthesis of oxalate-based $\mathrm{Mn}$ (II) complexes did not succeed a lot due to the high insolubility of manganese oxalate $\left(\mathrm{Mn}^{\mathrm{II}}\left(\mathrm{C}_{2} \mathrm{O}_{4}\right) \cdot 2 \mathrm{H}_{2} \mathrm{O}\right)$, a new 2D polymeric $\mathrm{Mn}(\mathrm{II})$ salt has been synthesized by slow evaporation at room temperature and its structure has been determined by single-crystal $\mathrm{X}$-ray diffraction. The structure was solved by direct methods and refined to conventional agreement indices. The crystal structure is built from anionic, two-dimensional, honeycomb networks formed by the oxalatebridged $\mathrm{Mn}$ (II) ions, interleaved by 2,6-diaminopyridinium cations that are entrapped between the layers. The interactions between adjacent layers result from the extended network of intermolecular hydrogen bonds created by the mentioned cations and water molecules. The complex has been fully characterized by single crystal X-ray diffraction, FT-IR and UV-Vis spectroscopy, Rietveld refinement, TGA-DSC analysis and magnetic susceptibility. The title compound exhibits antiferromagnetic coupling between $\mathrm{Mn}$ (II) centres.
\end{abstract}

Keywords. 2D coordination polymer; manganese; oxalate; magnetism.

\section{Introduction}

Coordination polymers (CPs) are of rising interest because of their fascinating topologies and dimensionality associated with both structural and functional versatility. Various attempts to build high-dimensional CPs with intriguing architectures were successful through the multitude of $\mathrm{N}$-donor ligands such as 1,10-phenanthroline derivatives, ${ }^{1}$ benzidine ligand ${ }^{2}$ and dipyridylbased ligand $^{3,4}$ as well as O-donor ligands including $o$-phthalic acid ${ }^{5}$ and carboxylic acid, ${ }^{6}$ due to their excellent coordinating ability. And among this wide variety of ligands, the oxalate ion was proven to be one of the most useful ligand, and played a prominent role by conferring electronic, ${ }^{7}$ photochemical, ${ }^{8}$ magnetic ${ }^{9}$ and optical ${ }^{10}$ properties on those materials. Because, oxalate ion acts as a rigid bidentate ligand that can facilitate the formation of extended structures by bridging $3 d$ metals.
The 2D honeycomb structure is the most common for the oxalate $\mathrm{CP}$ structures. ${ }^{11,12}$ It offers exciting opportunities in the fields of molecular magnetism. Accordingly, complexation of transition metals (as spin carrying centres) with the oxalate ions (as bridging units and mediator for magnetic spin interaction) creates a variety of molecular magnets ${ }^{13}$ with short-range and long-range magnetic ordering behaviour and arouse interest in the organic/inorganic chemistry community. In this field, significant research have been devoted to manganese oxalate complexes ${ }^{14-18}$ and to analysing the structural features and physical properties of the compounds as molecular magnets. ${ }^{19-21}$

We have extended our investigations on transition metal oxalate complexes and herein report the synthesis, crystal structure, spectroscopic studies, thermal analysis, Rietveld refinement and magnetic measurements of a new $2 \mathrm{D} \mathrm{Mn}$ (II) coordination polymer, aiming for valuable applications.

\footnotetext{
*For correspondence

Electronic supplementary material: The online version of this article (https://doi.org/10.1007/s12039-018-1427-2) contains supplementary material, which is available to authorized users.
} 


\section{Experimental}

\subsection{Materials and methods}

High purity manganese(II) sulphate monohydrate (SigmaAldrich, Germany), oxalic acid dihydrate (Prolabo, France) and 2,6-diaminopyridine (Sigma-Aldrich, Germany) were used without purification.

Elemental analyses for carbon, nitrogen and hydrogen were performed on a Flash 2000 Organic Elemental Analyser, CHNS-O analyser by Thermo Scientific (Centre of Scientific Instrumentation of the University of Granada). The infrared spectrum was recorded in the range $4000-400 \mathrm{~cm}^{-1}$ on a Bruker Tensor 27 FT-IR spectrometer, while the UVVis spectrum of the title compound in aqueous solution was recorded in the range 200-800 nm using UV-1800-Shimadzu Scientific Instruments (Department of Inorganic Chemistry of the University of Granada). XRD powder pattern was obtained using a D2 Phaser Bruker diffractometer equipped with a $\mathrm{Cu}$ anticathode $(\mathrm{Cu} \mathrm{K} \alpha$ radiation $\lambda=1.54056 \AA)$ at room temperature (Department of Inorganic Chemistry of the University of Granada). Thermogravimetric analysis was recorded in air using a Mettler-Toledo TGA/DSC1 Thermogravimetric Analyser in the range from 36 to $950{ }^{\circ} \mathrm{C}$ (Centre of Scientific Instrumentation of the University of Granada). Magnetic susceptibility measurements were performed on powdered polycrystalline sample using a Quantum Design MPMS 5XL SQUID magnetometer operating in the range of 2-300 K (Centre of Scientific Instrumentation of the University of Granada). Empiric correction for diamagnetism of $-308.78 \mathrm{emu} \mathrm{mol}^{-1}$, estimated by the use of Pascal's constants, ${ }^{22}$ was made for all the constituent atoms.

\subsection{Synthesis}

Brownish prismatic crystals suitable for X-ray analysis were obtained from the solution after almost two weeks of slow evaporation. Under continuous stirring at $373 \mathrm{~K}$, an aqueous solution $\left(10 \mathrm{~cm}^{3}\right)$ of manganese(II) sulphate monohydrate, $\mathrm{MnSO}_{4} \cdot \mathrm{H}_{2} \mathrm{O}(1 \mathrm{mmol}, 197.20 \mathrm{mg})$ was added dropwise to a water/acetone solution $\left(10 \mathrm{~cm}^{3}\right)$ of oxalic acid dihydrate, $\mathrm{H}_{2} \mathrm{C}_{2} \mathrm{O}_{4} \cdot 2 \mathrm{H}_{2} \mathrm{O}$ (1 mmol, $126.50 \mathrm{mg}$ ). After $15 \mathrm{~min}$ of stirring, a solution of 2,6-diaminopyridine, $\mathrm{C}_{5} \mathrm{H}_{7} \mathrm{~N}_{3}$ ( 2 mmol, 218.20 $\mathrm{mg}$ ) dissolved in water/acetone $\left(30 \mathrm{~cm}^{3}\right)$ was added dropwise with continuous stirring to the mixture until $\mathrm{pH} \approx 5$. The solution was filtered off and the filtrate was heated for further $3 \mathrm{~h}$, then left at room temperature in a petri dish. The elemental analytical results for carbon, hydrogen and nitrogen are close to the calculated values. Calculated: C: $29.64, \mathrm{H}: 3.42, \mathrm{~N}$ : 12.96\%; Found C: $30.49, \mathrm{H}: 4.01, \mathrm{~N}: 13.32 \%$.

\section{$2.3 X$ X-Ray crystallography}

Suitable single crystal of the title compound was carefully selected under a polarizing microscope and glued to a glass fibre then mounted on an Enraf-Nonius CAD-4 diffractometer $^{23}$ equipped with monochromatic graphite Mo $\mathrm{K} \alpha$ radiation $(\lambda=0.71069)$. Data were collected at room temperature. The unit cell parameters were determined based upon 25 reflections in the $2^{\circ} \leq \theta \leq 10^{\circ}$ range and they were refined using the least-squares method in the $10^{\circ} \leq \theta \leq 15^{\circ}$ range. The reflection intensities were collected up to $\theta=27^{\circ}$ with two standard reflections for intensities and orientation control. The crystal structure was solved using direct methods using the SHELX- $97^{24}$ computer program included in the WinGX software package ${ }^{25}$ and refined by full matrices least squares against $\mathrm{F}^{2}$ using SHELXL-2014. ${ }^{26}$

All non-hydrogen atoms were refined anisotropically. Water molecules' hydrogen atoms were located from the Fourier difference maps. The $\mathrm{O}-\mathrm{H}$ bond lengths were restrained to a value of $0.85(1) \AA$ and the $\mathrm{H} \cdot \mathrm{H}$ distances were restrained to a value of 1.387(1) $\AA$. Amine hydrogen atoms of 2,6-diaminopyridinium cations were positioned geometrically as riding atoms $(\mathrm{N}-\mathrm{H}=0.86 \AA$ ) using adequate HFIX instructions and refined with AFIX instructions while aromatic $\mathrm{C}-\mathrm{H}$ and $\mathrm{N}-\mathrm{H}$ hydrogen atoms were simply located from the Fourier difference maps. The empirical absorption corrections were based on a $\psi$-scan. The structural graphics were created with the DIAMOND program ${ }^{27}$ and Mercury. ${ }^{28}$ Crystal data and experimental details for $\mathbf{1}$ are contained in Table 1. Selected bond distances and angles are listed in Table S1 in Supplementary Information.

\section{Results and Discussion}

\subsection{Description of the structure}

Single crystal X-ray diffraction analysis revealed that the title compound, catena-[bis(2,6-diaminopyridinium) tris $\left(\mu_{2}\right.$-oxalato)-dimanganese(II) trihydrate] (1), crystallizes in the monoclinic space group $P 2_{1} / n$. The asymmetric unit consists of a binuclear complex anion $\left[\mathrm{Mn}_{2}\left(\mathrm{C}_{2} \mathrm{O}_{4}\right)_{3}\right]^{2-}$, two protonated 2,6-diaminopyrine cations $\left[\mathrm{C}_{5} \mathrm{H}_{8} \mathrm{~N}_{3}\right]^{+}$and three uncoordinated water molecules. In the complex anion, two crystallographically independent $\mathrm{Mn}^{2+}$ atoms with similar coordination environments are confirmed as +2 charged by bond valence sums (sums 2.10 and 2.11). ${ }^{29}$ Each $\mathrm{Mn}^{2+}$ has six-coordinate octahedral geometry with six oxygens from three different oxalates. The two manganese ions are linked through a planar oxalate group in the usual bis(bidentate) fashion, leading to a metal-metal separation of 5.647(2) $\AA$. A drawing of the asymmetric unit showing the labelling scheme is given in Figure 1.

The first manganese ion is more distorted than the second with $\mathrm{ID}_{\mathrm{d}}=0.011 \%$ and $\mathrm{ID}_{\mathrm{a}}=0.221 \%$ for $\mathrm{Mn} 1$ and $\mathrm{ID}_{\mathrm{d}}=0.006 \%$ and $\mathrm{ID}_{\mathrm{a}}=0.218 \%$ for Mn2. Polyhedral distance and angle distortions in both $\mathrm{Mn} 1 \mathrm{O}_{6}$ and

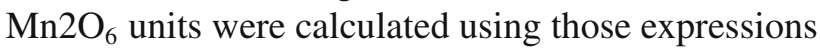

$\mathrm{ID}_{\mathrm{d}}=\left[\sum_{\mathrm{i}=1}^{6} \frac{\left|\mathrm{d}_{\mathrm{i}}-\mathrm{d}_{\mathrm{m}}\right|}{6 \times \mathrm{d}_{\mathrm{m}}}\right]$ 
Table 1. Crystal data refinement results of $\left\{\left(\mathrm{C}_{5} \mathrm{H}_{8} \mathrm{~N}_{3}\right)_{2}\left[\mathrm{Mn}_{2}\left(\mathrm{C}_{2} \mathrm{O}_{4}\right)_{3}\right] \cdot 3 \mathrm{H}_{2} \mathrm{O}\right\}_{n}$.

\begin{tabular}{|c|c|}
\hline Formula & $\left(\mathrm{C}_{5} \mathrm{H}_{8} \mathrm{~N}_{3}\right)_{2}\left[\mathrm{Mn}_{2}\left(\mathrm{C}_{2} \mathrm{O}_{4}\right)_{3}\right] \cdot 3 \mathrm{H}_{2} \mathrm{O}$ \\
\hline Formula weight $\left(\mathrm{g} \mathrm{mol}^{-1}\right)$ & 648.27 \\
\hline Temperature $(\mathrm{K})$ & $298(2)$ \\
\hline Wavelength $(\AA)$ & 0.71069 \\
\hline Space group & $P 2_{1} / n$ \\
\hline \multicolumn{2}{|l|}{ Unit cell dimensions } \\
\hline $\mathrm{a}(\AA)$ & $9.756(3)$ \\
\hline $\mathrm{b}(\AA)$ & $16.743(5)$ \\
\hline$c(\AA)$ & $15.420(1)$ \\
\hline$\beta(0)$ & $97.53(5)$ \\
\hline Cell volume $\left(\AA^{3}\right)$ & $2497.1(11)$ \\
\hline $\mathrm{Z}$ & 4 \\
\hline Absorption coefficient $\left(\mathrm{mm}^{-1}\right)$ & 1.096 \\
\hline Crystal size $\left(\mathrm{mm}^{3}\right)$ & $0.41 \times 0.34 \times 0.2$ \\
\hline Crystal sharp; colour & prism; brown \\
\hline Theta range for data collection $\left(^{\circ}\right)$ & $2.34-26.97$ \\
\hline Limiting indices & $-12 \leq h \leq 1 ;-21 \leq k \leq 1 ;-19 \leq l \leq 19$ \\
\hline Absorption correction; $\mathrm{T}_{\min } ; \mathrm{T}_{\max }$ & psi-scan; $0.6461 ; 0.7351$ \\
\hline Reflections collected & 6626 \\
\hline Independent reflections & $5437\left[\mathrm{R}_{\mathrm{int}}=0.029\right]$ \\
\hline Observed reflections $[\mathrm{I}>2 \sigma(\mathrm{I})]$ & 3204 \\
\hline Refinement method & Full-matrix least-squares on $\mathrm{F}^{2}$ \\
\hline Final $R$ indices $[\mathrm{I}>2 \sigma(\mathrm{I})]$ & $\mathrm{R}(\mathrm{F})=0.042 ; w \mathrm{R}\left(\mathrm{F}^{2}\right)=0.109$ \\
\hline Residuals $\left(\mathrm{e} \AA^{-3}\right)$ & $0.49 ;-0.30$ \\
\hline Goodness of fit $(\mathrm{S})$ & 1.02 \\
\hline
\end{tabular}

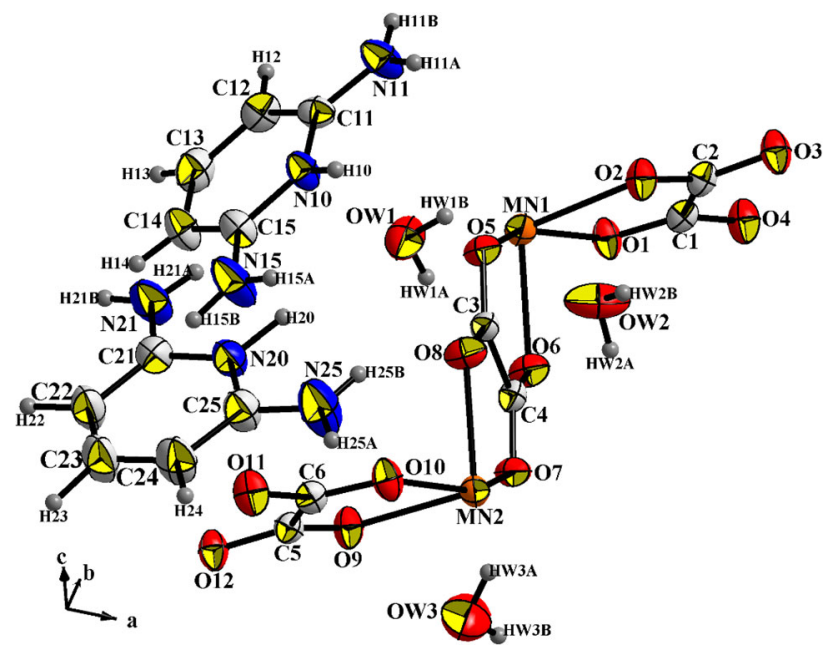

Figure 1. The structural unit of $\mathbf{1}$, showing the atom-numbering scheme. Thermal ellipsoids are drawn at the $40 \%$ probability level for non-H atoms.

and

$\mathrm{ID}_{\mathrm{a}}=\left[\sum_{\mathrm{i}=1}^{15} \frac{\left|\mathrm{a}_{\mathrm{i}}-\mathrm{a}_{\mathrm{m}}\right|}{15 \times \mathrm{a}_{\mathrm{m}}}\right]$

where $d_{m}$ is the average $\mathrm{Mn}-\mathrm{O}$ distance and $\mathrm{a}_{\mathrm{m}}$ is the average $\mathrm{O}-\mathrm{Mn}-\mathrm{O}$ angle.
In the asymmetric unit, oxalate ligands are planar, the root-mean-square deviation of terminal oxalate ions from their mean planes are 0.0375 and 0.0306 $\AA$ while the value for the bridging oxalate ion is $0.0090 \AA$. The dihedral angle between terminal/bridging least-square planes is 77.42(9) ${ }^{\circ}$ and $80.83(9)^{\circ}$. C$\mathrm{C}$ distances between 1.546(4) and 1.549(4) $\AA$ and C-O distances from $1.242(4)$ to $1.251(4) \AA$ are in the typical range reported for $2 \mathrm{D} \mathrm{Mn}^{\mathrm{II}}$ oxalate compounds $^{30}$ and in good agreement with our previous work on $1 \mathrm{D} \mathrm{Mn}^{\mathrm{II}}$ oxalate compound. The mean deviations of the pyridine rings of the cations are of 0.0012 and $0.0067 \AA$ from the mean planes. Amine groups of each cation are almost coplanar with the pyridine rings.

In the structure packing of the compound, $\mathrm{Mn}^{\mathrm{II}}$ ions are connected each to three bridging oxalates, creating a honeycomb motif. Hence, the structure can be described as composed of infinite manganese-oxalate layers, perpendicular to the $\overrightarrow{\mathbf{c}}$ axis (Figure 2(b)). The separation of the manganese atoms along the three mentioned oxalate bridges (5.628(1), 5.647(2) and 5.697(1) $\AA$ ) are in the range observed for other manganese-oxalato compounds ${ }^{31,32}$ and generate slightly irregular hexagonal channels. 


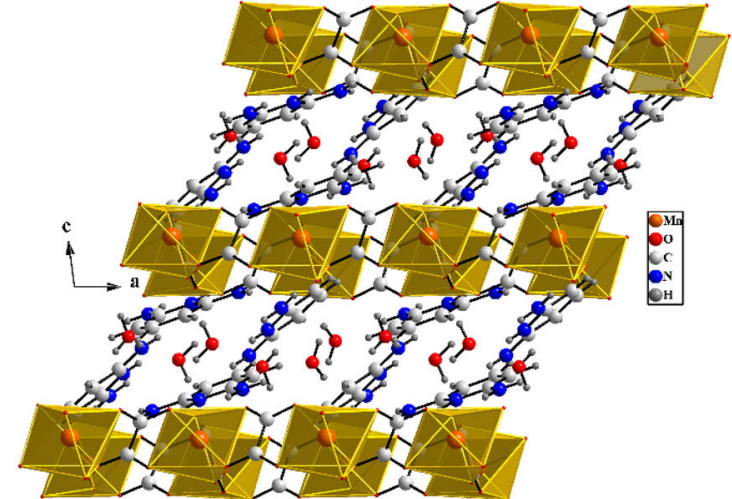

(a)

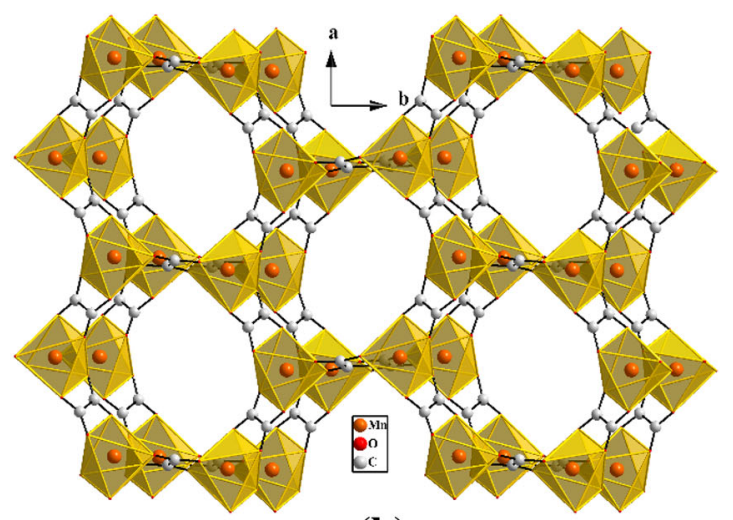

(b)

Figure 2. Layered sector of the title compound: (a) [010] projection; and (b) [001] projection for anionic layers only.

The charged components are connected by an extensive hydrogen-bonding network. Yet, the honeycomb layers are held together by hydrogen bonds via the water molecules of crystallization and 2,6diaminopyridinuim cations, situated between the layers as depicted in Figure 2(a). In fact, 2,6diaminopyridinuim cations coordinate anionic layers and water molecules via $\mathrm{N}-\mathrm{H}$... O hydrogen bonds. As shown in Figure 3(a) and Figure 3(b), both amine and pyridine nitrogen atoms act as hydrogen-bond donors and establish strong hydrogen bonds towards different oxygen atoms of both $\left\{\left[\mathrm{Mn}_{2}\left(\mathrm{C}_{2} \mathrm{O}_{4}\right)_{3}\right]^{2-}\right\}_{\mathrm{n}}$ layers and water molecules. These act at the same time as hydrogen-bond donors via $\mathrm{O}-\mathrm{H} \cdots \mathrm{O}$ hydrogen bonds involving their oxygen atoms and hold together three different anionic planes, enhancing the stability of the crystal as depicted in Figure 3(c). An additional stability of the structure is provided by $\pi-\pi$ interactions between the anti-parallel pyridine rings of 2,6-diaminopyridinium cations, with centroid-centroid distance of $3.667 \AA$ (Figure S1 in Supplementary Information).

\subsection{Infrared spectroscopy}

With the molecular structure of 1 being established crystallographically, further evidence of complexation was obtained from the spectral data. Indeed, the IR spectrum of 1 (Figure S2 in Supplementary Information) shows characteristic vibrations of the bridging oxalato ligand. In fact, a strong band at $1602 \mathrm{~cm}^{-1}$ shifted to lower wavenumber due to the ligand deprotonation, which can be characteristic of $v_{\text {as }}(\mathrm{C}-\mathrm{O})$ asymmetric vibration of the oxalate. The peak at $1303 \mathrm{~cm}^{-1}$ can be attributed to symmetric vibrations $v_{\mathrm{s}}(\mathrm{C}-\mathrm{O})$ while the peak at 781 $\mathrm{cm}^{-1}$ can be attributed to $\delta(\mathrm{O}-\mathrm{C}-\mathrm{O})$ supports the oxalate presence in a bis-bidentate coordination mode. ${ }^{33,34}$

\subsection{Powder XRD analysis}

The powder diffraction measurement was performed under Bragg-Brentano geometry in the $5^{\circ}-50^{\circ}$ range with step of $0.02^{\circ}$. Rietveld refinement was performed using the FullProf Suite program, ${ }^{35}$ whereas pattern indexing was carried out by means of the auto-indexing program TREOR. ${ }^{36}$ As depicted in Figure 4, the absence of additional peaks in the diffraction pattern and the linearity of the background confirmed the purity of the powder sample based on the fully consistent results with those obtained from the single crystal diffraction data.

\subsection{UV-Vis absorption spectrum}

The title compound has good solubility in distilled water. The UV-Vis absorption spectrum in distilled water (Figure 5) exhibits two absorption bands at 240 and $329 \mathrm{~nm}$. The lower energy band can be considered as $\pi \rightarrow \pi^{*}$ transition of the aromatic rings, while the higher one can be attributed to LMCT transition. Failure to observe the manganese(II) $\mathrm{d}$-d band may be due to the weakness of absorption.

\subsection{Thermal analysis}

In order to characterize the compound more fully in terms of thermal stability, its thermal behaviour was carried out for powder sample of $\mathbf{1}$ in air from 36 to $950{ }^{\circ} \mathrm{C}$ under a heating rate of $10^{\circ} \mathrm{Cmin}^{-1}$ (Figure $\mathrm{S} 3$ in Supplementary Information). The weight loss in the range upto $90{ }^{\circ} \mathrm{C}$ corresponds to the removal of the three water molecules (observed, 7.2\%; calculated, $8.3 \%$ ). The result shows good agreement with the formula of the compound. A major thermogravimetric loss step of almost $49 \%$ of the compound mass, (calculated, 


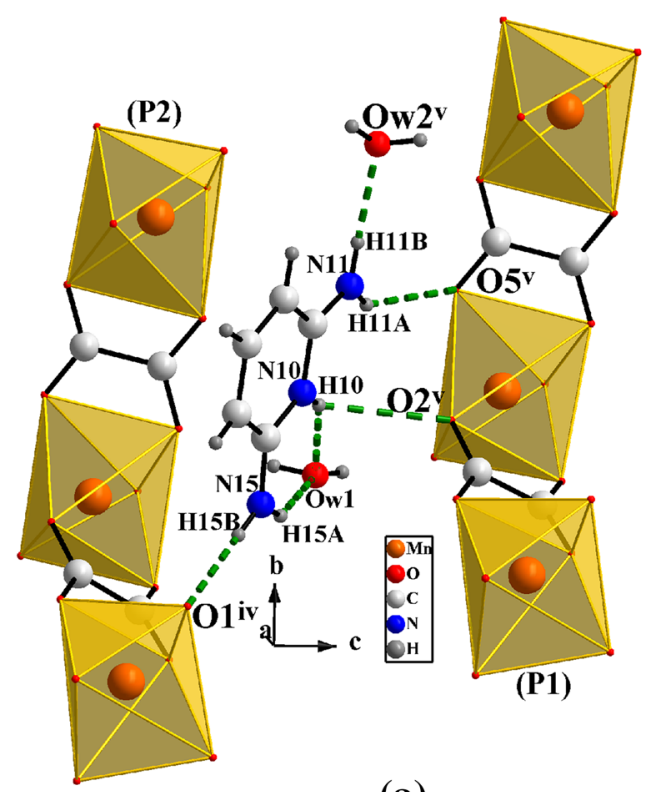

(a)

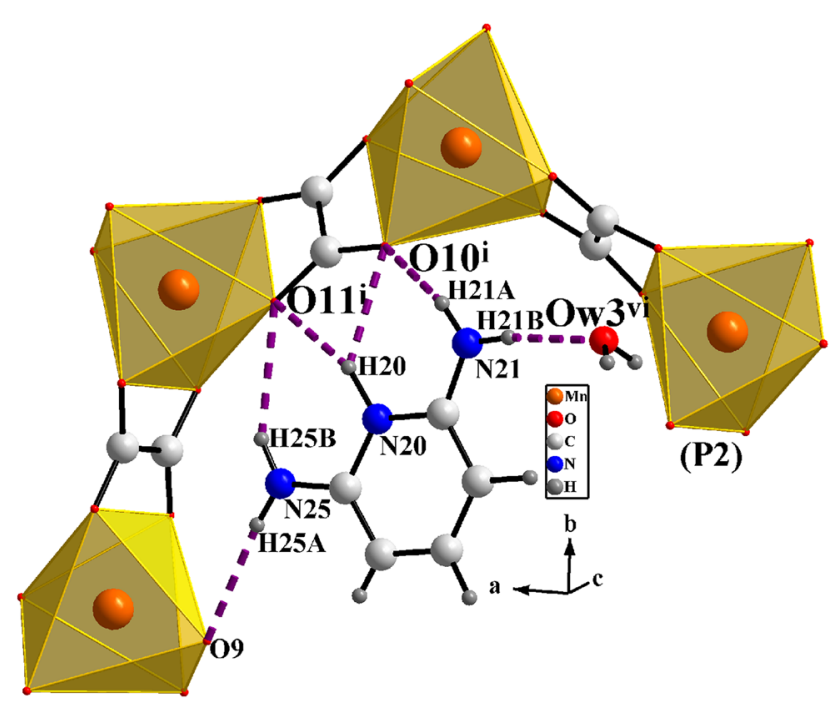

(b)

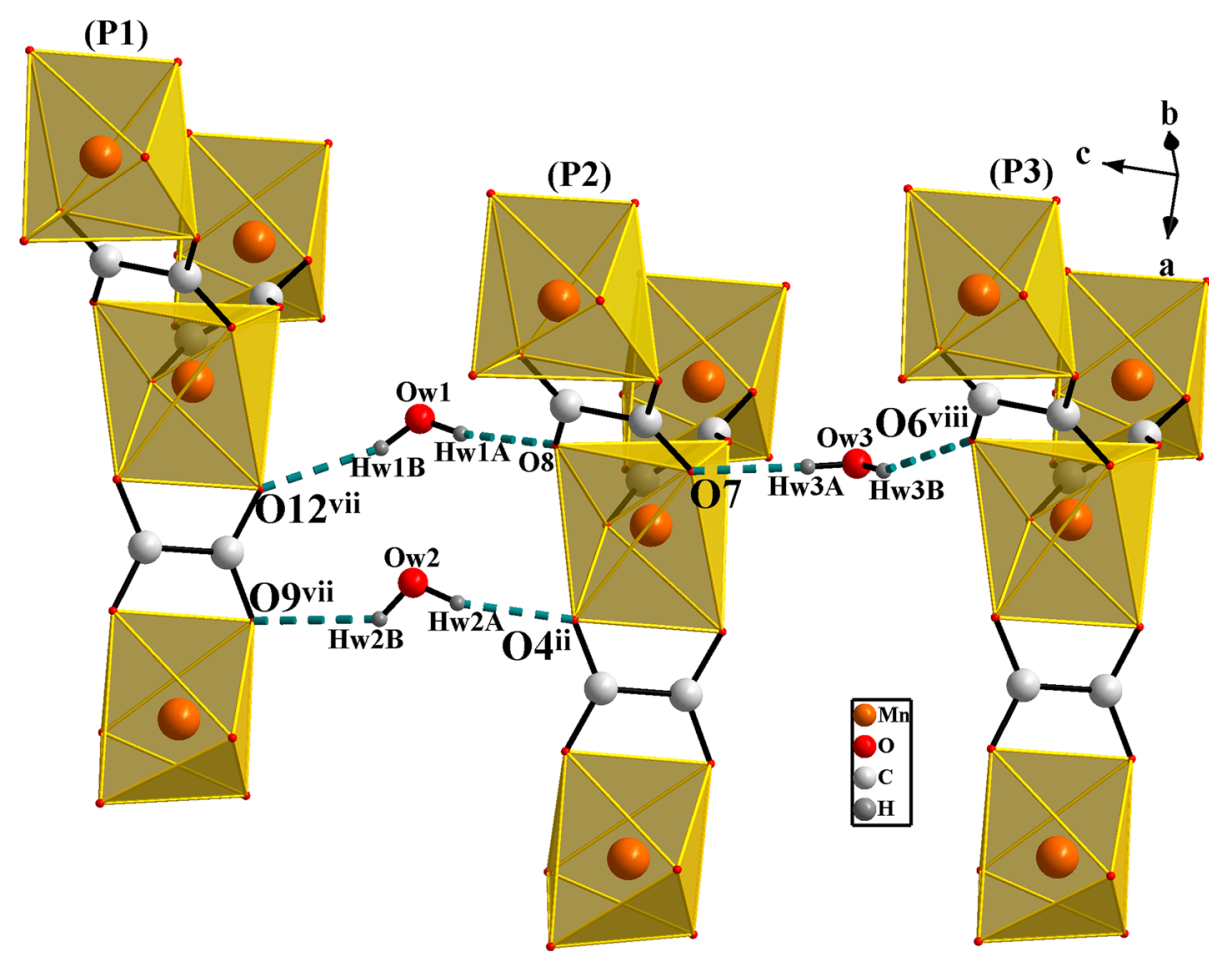

(c)

Figure 3. View of the hydrogen bonds formed by, (a) the first organic cation (green dashed lines), (b) the second organic cation (purple dashed lines) and (c) water molecules (turquoise dashed lines). [Symmetry codes: (i) $-\mathrm{x}+1 / 2, \mathrm{y}+1 / 2,-\mathrm{z}+1 / 2$; (ii) $-\mathrm{x}+3 / 2, \mathrm{y}-1 / 2,-\mathrm{z}+1 / 2$; (iv) $-\mathrm{x}+1 / 2, \mathrm{y}-1 / 2,-\mathrm{z}+1 / 2$; (v) $-\mathrm{x}+1$, $-\mathrm{y},-\mathrm{z}+1$; (vi) $-\mathrm{x},-\mathrm{y},-\mathrm{z}$; (vii) $\mathrm{x}+1 / 2,-\mathrm{y}-1 / 2, \mathrm{z}+1 / 2$; (viii) $-\mathrm{x}+1,-\mathrm{y},-\mathrm{z}$.$] .$

47\%), was detected which may be due to loss of organic cations and liberation of CO. The next loss step of $13.2 \%$ (calculated, 12.9\%) may be attributed to another liberation of $\mathrm{CO}$. Thus, the final residue is the formation of the metal oxide $\mathrm{Mn}_{2} \mathrm{O}_{3}$ (observed, 23.6\%; calculated, $24.3 \%$ ).

\subsection{Magnetic susceptibility measurements}

The temperature dependence of $\chi_{\mathrm{m}}$ and $\chi_{\mathrm{m}} \mathrm{T}\left(\chi_{\mathrm{m}}\right.$ being the magnetic susceptibility for one $\mathrm{Mn}$ (II) ion) was examined in the temperature range of 2-300 K (Figure 6). 
The magnetic susceptibility plot, $\chi_{\mathrm{m}} \mathrm{vs} \mathrm{T}$, shows a broad maximum indicating the presence of antiferromagnetic ordering with a Néel temperature $\left(\mathrm{T}_{\mathrm{N}}\right)$ of 12 $\mathrm{K}$. The inverse susceptibility plot, $\chi_{\mathrm{m}}^{-1}$ vs $\mathrm{T}$ (plot not shown), shows linear behavior above $30 \mathrm{~K}$, its thermal evolution follows the Curie-Weiss law with $\mathrm{C}=4.69$ emu $\mathrm{mol}^{-1} \mathrm{~K}$ and $\theta=-13.44 \mathrm{~K}$. Due to the lack of an easy applicable model to fit the experimental data, the magnetic properties of the two-dimensional homometallic $\left\{\left[\mathrm{M}_{2}\left(\mathrm{C}_{2} \mathrm{O}_{4}\right)_{3}\right]^{2-}\right\}_{\mathrm{n}}$ layers were mostly derived from that Curie-Weiss expression. The negative Weiss constant value of -29.8 (7) $\mathrm{K}$ for $\mathrm{Cu}$ (II) ${ }^{37},-53 \mathrm{~K}$ for $\mathrm{Fe}(\mathrm{II})$ and $-92.1 \mathrm{~K}$ for $\mathrm{Co}(\mathrm{II})^{38}$ have always suggested an antiferromagnetic interaction between the metal centers through the oxalato-bridge. For the Mn(II) homometallic 2D oxalate-bridged compounds, an almost identical behavior as our compound, was reported for the complex $\left.\left[\mathrm{NH}\left(\mathrm{C}_{2} \mathrm{H}_{5}\right)_{3}\right]\left[\mathrm{Mn}_{2}\left(\mathrm{C}_{2} \mathrm{O}_{4}\right)_{3}\right] \cdot\left(5 \mathrm{H}_{2} \mathrm{O}\right)\right]^{15}$ with a Weiss constant of $-14.2 \mathrm{~K}$.

The observed $\chi_{\mathrm{m}} \mathrm{T}$ values gradually decrease upon cooling. At room temperature, $\chi_{\mathrm{m}} \mathrm{T}$ shows the asymptotic limit of $4.36 \mathrm{emu} \mathrm{mol}^{-1} \mathrm{~K}$, slightly lower than the expected value for an "isolated" $\mathrm{Mn}^{2+}$ ion (4.38 emu $\left.\mathrm{mol}^{-1} \mathrm{~K}\right)$. The effective magnetic moment per $\mathrm{Mn}(\mathrm{II})$ ion, determined from the equation $\mu_{\text {eff }}=2.828\left(\chi_{\mathrm{m}} \mathrm{T}\right)^{1 / 2}$ is also around $5.91 \mu_{\mathrm{B}}$ and in good agreement with the expected value.

Accordingly, and taking into account the twodimensional character of the title compound, the geometry of the asymmetric unit of the compound and the slight difference in the $\mathrm{Mn} \cdots \mathrm{Mn}$ distances previously discussed, the experimental data of $\chi_{\mathrm{m}} \mathrm{T}$ were first fitted to the theoretical dimer model expression (eq. 3) based on Heisenberg Hamiltonian $\mathrm{H}=-2 \mathrm{~J} . \mathrm{S}_{1} . \mathrm{S}_{2} \cdot{ }^{39}$

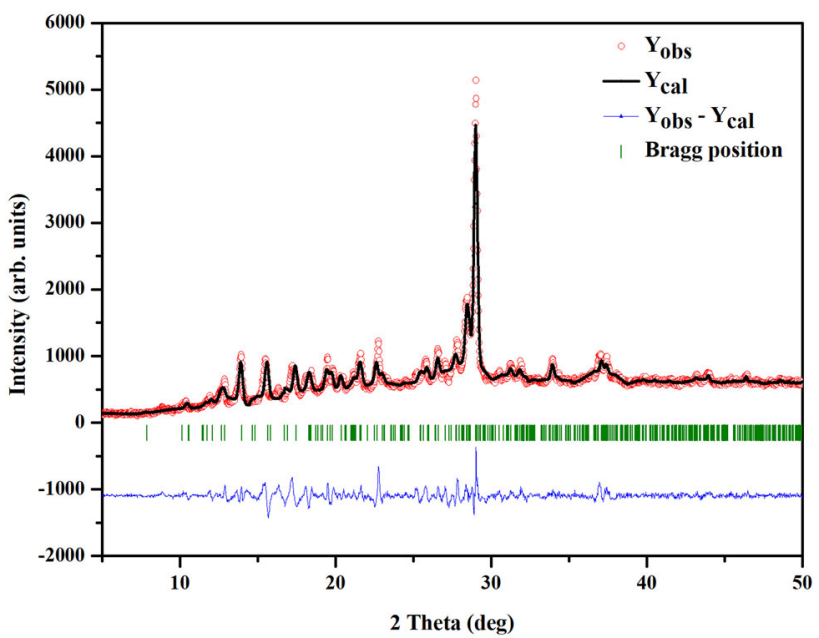

Figure 4. Rietveld refinement plot for compound 1 showing the observed, calculated and difference patterns. The Bragg reflections are indicated by vertical bars.

$\rho$ is the fraction of paramagnetic impurity in the sample, $\mathrm{N}_{\alpha}$ is the temperature independent paramagnetism and the other symbols have their usual meanings. The best fits shown in Figure 6 correspond to $\mathrm{g}=2.18$, $\mathrm{J}=-1.75 \mathrm{~cm}^{-1}, \rho=0.035, \mathrm{~N}_{\alpha}=-0.002$ and $\mathrm{J}^{\prime}=$ $-2.14 \mathrm{~cm}^{-1}$ with $\mathrm{R}^{2}=0.9998$ and 0.9994 , respectively.

As the $2 \mathrm{D}$ system was regarded magnetically as an isolated $1 \mathrm{D}$ chain with $\mu$-oxalato bridges, the result was compared to both 1D and 2D mixed ligands homometallic units including $[\mathrm{Mn}(\mu-\mathrm{ox})]_{\mathrm{n}}$ chains, and shown in Table 2. The survey of $J$ values for the $\mathrm{Mn}$ (II) chains shows that the obtained values in this study are within the expected range of -0.58 to $-3 \mathrm{~cm}^{-1}$. Many factors contribute to the variation of the magnetic coupling along the oxalate bridge such as the replacement of

$$
\begin{aligned}
\chi_{\mathrm{m}} \mathrm{T}= & \frac{2 \mathrm{~N}_{\mathrm{A}} \mu^{2} \mathrm{~g}^{2} \times(1-\rho)}{\mathrm{k}} \\
& \times \frac{\left[55+30 \mathrm{e}^{-10 \mathrm{~J} / \mathrm{kT}}+14 \mathrm{e}^{-18 \mathrm{~J} / \mathrm{kT}}+5 \mathrm{e}^{-24 \mathrm{~J} / \mathrm{kT}}+\mathrm{e}^{-28 \mathrm{~J} / \mathrm{kT}}\right]}{\left[11+9 \mathrm{e}^{-10 \mathrm{~J} / \mathrm{kT}}+7 \mathrm{e}^{-18 \mathrm{~J} / \mathrm{kT}}+5 \mathrm{e}^{-24 \mathrm{~J} / \mathrm{kT}}+3 \mathrm{e}^{-28 \mathrm{~J} / \mathrm{kT}}+\mathrm{e}^{-30 \mathrm{~J} / \mathrm{kT}}\right]} \\
& +\frac{\mathrm{N}_{\mathrm{A}} \mu^{2} \mathrm{~g}^{2} \mathrm{~S}(\mathrm{~S}+1)}{\mathrm{k}}+\mathrm{N}_{\alpha} \mathrm{T}
\end{aligned}
$$

Then, the dimeric $\mathrm{Mn}(\mathrm{II})$ unit is taken as an effective classical spin system and $\chi_{\mathrm{m}}$ was fitted by using an infinite-chain model derived by Fisher ${ }^{40,41}$ with the corresponding theoretical expression (eq. 4a) and (eq. 4b).

$$
\begin{aligned}
& \chi_{m}=\frac{N \mu^{2} g^{2}}{3 k T} \cdot \frac{1+u}{1-u} \\
& u=\operatorname{coth}\left[\frac{J^{\prime} S(S+1)}{k T}\right]-\left[\frac{k T}{J^{\prime} S(S+1)}\right]
\end{aligned}
$$

oxygen by nitrogen atoms in the $\mathrm{Mn}$ (II) coordination polyhedron which allows more electron density to be involved in the orbital overlap between the metal and oxalate. In our case, the magnitudes of the antiferromagnetic interaction $\left(-1.75\right.$ and $\left.-2.14 \mathrm{~cm}^{-1}\right)$ lie in the higher range for $\mathrm{Mn}$ (II) oxalate-bridged compounds despite the relatively long $\mathrm{Mn} \cdots$ Mn distance (5.697(1) $\AA$ ) which is unexpected for the more electronegative $\mathrm{MnO}_{6}$ coordination environment. Further quantum 


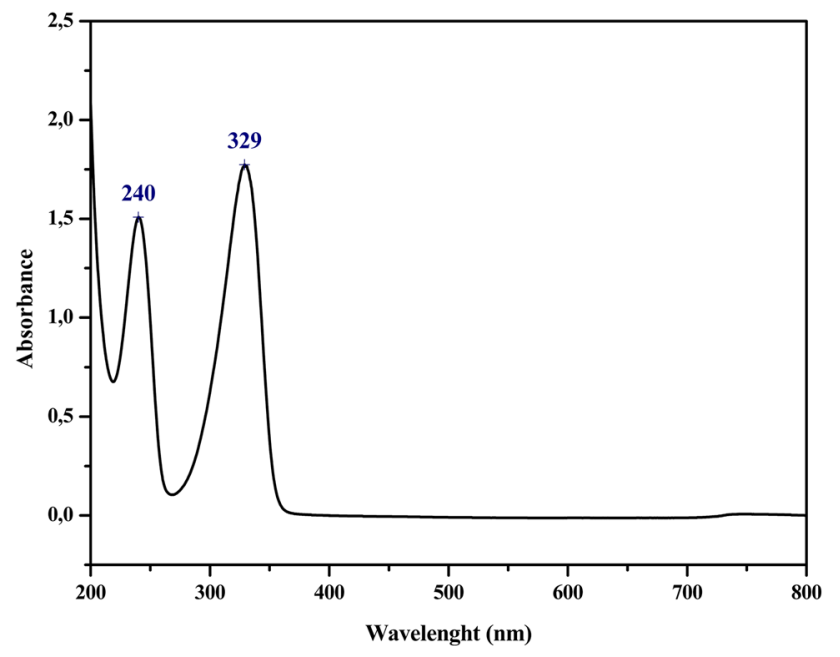

Figure 5. UV-Vis absorption spectrum of compound $\mathbf{1}$ (Concentration, $5 \times 10^{-3} \mathrm{M}$, path length, $1 \mathrm{~cm}$ ).

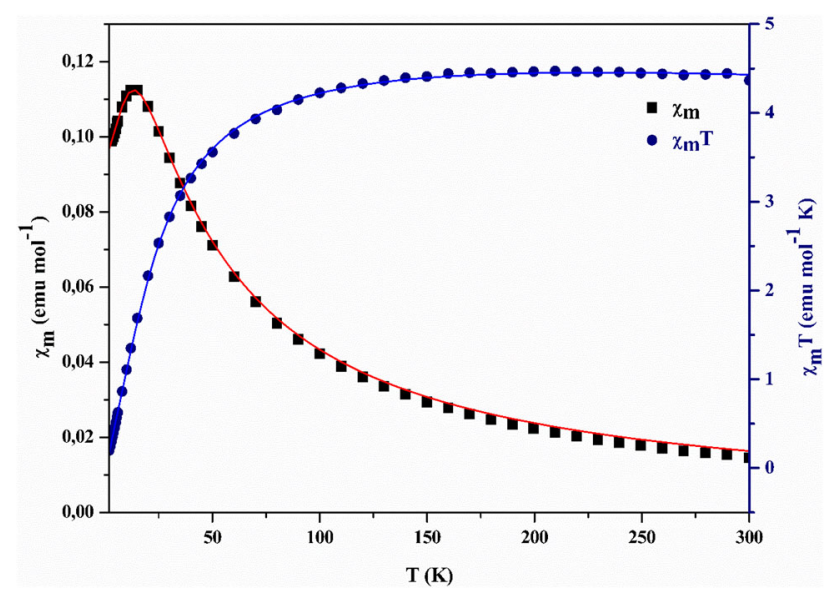

Figure 6. Plots of the temperature dependence of $\chi_{\mathrm{m}}$ (solid squares) and $\chi_{\mathrm{m}} \mathrm{T}$ (solid circles). The solid line represents the best-fit using the equations and parameters described in the text. chemical calculations is required to determine the magnetic coupling between $\mathrm{Mn}$ (II) in the two-dimensional honeycomb oxalate-bridge anionic layers ${ }^{47,48}$ to confirm the experimental results.

\section{Conclusions}

In conclusion, a new 2D polymeric structure of manganese(II) ions bridged by oxalate ligands has been presented. The compound has been successfully synthesized by slow evaporation at room temperature and its structure has been fully characterized by single crystal XRD and FT-IR.

The catena-[bis(2,6-diaminopyridinium) $\operatorname{tris}\left(\mu_{2}-\right.$ oxalato)-dimanganese(II) trihydrate] compound exhibits a supramolecular assembly of 3D network constructed by $\mathrm{N}-\mathrm{H} \cdots \mathrm{O}$ and $\mathrm{O}-\mathrm{H}$. . O hydrogen bonds and $\pi-\pi$ interactions between adjacent 2D $\left\{\left[\mathrm{Mn}_{2}\left(\mathrm{C}_{2} \mathrm{O}_{4}\right)_{3}\right]^{2-}\right\}_{\mathrm{n}}$ layers.

The purity of the polycrystalline powder was checked by a Rietveld refinement. The thermal behaviour was in full agreement with the structural data. The material may be magnetically comparable to other typical two-dimensional manganese(II) systems showing weak antiferromagnetic coupling between $\mathrm{Mn}$ (II) centres. Further experiments which aim to study optical band gap, thermal and magnetic behaviour of different 2D bimetallic $\mathrm{Mn} / 3 \mathrm{~d}$-metal and mixed valence $\mathrm{Mn}^{\mathrm{II}}-\mathrm{Mn}^{\mathrm{III}}$ oxalate-bridged compounds are ongoing.

\section{Supplementary Information (SI)}

Crystallographic data and full lists of bond lengths and angles have been deposited with the Cambridge Crystallographic Data Centre, CCDC No. 1434416. Copies of this

Table 2. Magnetostructural data for similar homometallic oxalato-bridged Mn(II) chain-like complexes.

\begin{tabular}{lcccc}
\hline Compound & Chromophore & Ref & Mn $\cdots$ Mn distance $(\AA)$ & $J\left(\mathrm{~cm}^{-1}\right)$ \\
\hline$\left[\mathrm{Mn}\left(\mu-\left(\mathrm{C}_{2} \mathrm{O}_{4}\right)\right)(\mu-b p m)\right]_{\mathrm{n}}$ & $\mathrm{MnO}_{4} \mathrm{~N}_{2}$ & 42 & 5.61 & -3.0 \\
{$\left[\mathrm{Mn}\left(\mu-\left(\mathrm{C}_{2} \mathrm{O}_{4}\right)\right)_{2}(\mu-b p e)(b p e)_{2}\right]_{\mathrm{n}}$} & $\mathrm{MnO}_{4} \mathrm{~N}_{2}$ & 32 & 5.54 & -2.16 \\
{$\left[\mathrm{Mn}\left(\mu-\left(\mathrm{C}_{2} \mathrm{O}_{4}\right)\right)(b t z)_{2}\right]_{\mathrm{n}}$} & $\mathrm{MnO}_{4} \mathrm{~N}_{2}$ & 43 & 5.67 & $-2.16^{*}$ \\
{$\left[\mathrm{Mn}\left(\mu-\left(\mathrm{C}_{2} \mathrm{O}_{4}\right)\right)(b n z)_{2}\right]_{\mathrm{n}}$} & $\mathrm{MnO}_{4} \mathrm{~N}_{2}$ & & 5.70 and 5.73 & $-2.12^{*}$ \\
{$\left[\mathrm{Mn}\left(\mu-\left(\mathrm{C}_{2} \mathrm{O}_{4}\right)\right)\left(\mathrm{H}_{2} \mathrm{O}\right)\left(7 \mathrm{H}-p u r-\kappa \mathrm{N}^{9}\right)\right]_{\mathrm{n}}$} & $\mathrm{MnO}_{5} \mathrm{~N}$ & 44 & 5.60 & -1.99 \\
$\left.\left[\mathrm{Mn}\left(\mu-\left(\mathrm{C}_{2} \mathrm{O}_{4}\right)\right)\left(\mathrm{H}_{2} \mathrm{O}\right)_{2}\right] .(7 \mathrm{H}-a d e) \cdot\left(\mathrm{H}_{2} \mathrm{O}\right)\right\}_{\mathrm{n}}$ & $\mathrm{MnO}_{6}$ & & 5.71 & -1.82 \\
{$\left[\mathrm{Mn}\left(\mu-\left(\mathrm{C}_{2} \mathrm{O}_{4}\right)\right)(4 a t r)_{2}\right]_{\mathrm{n}}$} & $\mathrm{MnO}_{4} \mathrm{~N}_{2}$ & 7 & 5.60 & -1.74 \\
{$\left[\mathrm{Mn}\left(\mu-\left(\mathrm{C}_{2} \mathrm{O}_{4}\right)\right)(b p y)\right]_{\mathrm{n}}$} & $\mathrm{MnO}_{4} \mathrm{~N}_{2}$ & 19 & 5.62 & -1.20 \\
$\left.\left[\mathrm{Mn}\left(\mu-\left(\mathrm{C}_{2} \mathrm{O}_{4}\right)\right)(\mathrm{H})_{2}\right]_{3}\left(\mathrm{H}_{2} \mathrm{O}\right)\right\}_{\mathrm{n}}$ & $\mathrm{MnO}_{6}$ & 45 & 5.71 & -1.07 \\
{$\left[\alpha-\mathrm{Mn}\left(\mu-\left(\mathrm{C}_{2} \mathrm{O}_{4}\right)\right)\left(\mathrm{H}_{2} \mathrm{O}\right)_{2}\right]_{\mathrm{n}}$} & $\mathrm{MnO}_{6}$ & 46 & 5.63 & $-0.58^{*}$ \\
\hline
\end{tabular}

bpm = 2,2'-bipyrimidine; $b p e=$ bis(4-pyridyl)ethylene; $b t z=$ benzotriazole; $b n z=$ benzimidazole; pur = purine; $a d e$ $=$ adenine; 4atr $=4$-amine-1,2,4-triazole; bpy $=2,2$ '-bipyridine;

*Value reported as $J / k_{B}(\mathrm{~K})$ in the original paper and has been converted to $J\left(\mathrm{~cm}^{-1}\right)$ 
information may be obtained free of charge from The Director, CCDC, 12 Union Road, CAMBRIDGE, CB2 1EZ, UK (Fax: +44-1223-336-033; Email: deposit@ccdc.cam.ac.uk or http://www.ccdc.cam.ac.uk). $\pi-\pi$ stacking in the structure of compound 1 (Figure S1), IR spectrum of compound 1 (Figure S2), TGA-DSC curve for compound 1 (Figure S3) and selected bond lengths $(\AA)$ and angles $\left(^{\circ}\right)$ for $\mathbf{1}$ (Table S1) are given in Supplementary Information, available at www.ias. ac.in/chemsci.

\section{Acknowledgements}

Financial support from the Ministry of Higher Education and Scientific Research of Tunisia is gratefully acknowledged. H. S. also thanks, Dr. Elisa Barea (Department of Inorganic Chemistry, University of Granada) for support and advice during her short-term stay in the University of Granada, where most of the characterization of the reported compound was conducted.

\section{References}

1. Huang Y J, Pan Y R, Du G and Cao Y X 2016 Extended structures of two coordination polymers based on 1,10-phenanthroline derivatives: Preparation, structural characterization and properties J. Chem. Sci. 128 459

2. Lin H, Lu H, Le M, Luan J, Wang X and Liu G 2015 Three 2 D copper(II)/cadmium(II) coordination polymers based on semi-rigid/flexible bis-pyridyl-bis-amide ligands and 5-aminoisophthalate: Syntheses, structures and properties J. Chem. Sci. 1271275

3. Lin H, Sun J, Liu G, Wang X and Chen P 2017 Self-assembly, structures and properties of three new $\mathrm{Ni}$ (II) coordination polymers derived from two different bis-pyridyl-bis-amide ligands and two aromatic polycarboxylates J. Chem. Sci. 1299

4. Sarma B, Bharali S and Das D K 2016 Synthesis, crystal structure and Thermogravimetry of ortho-phthalic acid bridged coordination polymer of Copper(II) J. Chem. Sci. 128899

5. Sutradhar D, Chowdhury H, Koner S, Roy S and Ghosh B K 2016 Two new hexacoordinated coordination polymers of cadmium(II) containing bridging units only: Syntheses, structures and molecular properties J. Chem. Sci. 1281377

6. Thatituri S, Govindugari B and Chittireddy V R R 2017 Carboxylate-bridged $\mathrm{Cu}(\mathrm{II})$ coordination polymeric complex: synthesis, crystal structure, magnetic properties, DNA binding and electrochemical studies $J$. Chem. Sci. 1291171

7. García-Couceiro U, Olea D, Castillo O, Luque A, Román P, De Pablo P J, Gómez-Herrero J and Zamora F 2005 Scanning Probe Microscopy Characterization of Single Chains Based on a One-Dimensional Oxalato-Bridged Manganese(II) Complex with 4-Aminotriazole Inorg. Chem. 448343

8. Decurtins S, Schmalle H W, Schneuwly P and Oswald H R 1993 Photochemical Synthesis and Structure of a 3Dimensional Anionic Polymeric Network of an Iron(II)
Oxalato Complex with Tris(2,2'-bipyridine)iron(II) Cations Inorg. Chem. 321888

9. Decurtins S, Schmalle H W, Schneuwly P, Ensling J and Gütlich P 1994 A Concept for the Synthesis of 3-Dimensional Homo- and Bimetallic Oxalate-Bridged Networks $\left[\mathrm{M}_{2}(\mathrm{Ox})_{3}\right]_{\mathrm{n}}$. Structural, Mössbauer, and Magnetic Studies in the Field of Molecular-Based Magnets J. Am. Chem. Soc. 1169521

10. Duan C, Luo D, Shang R and Lin Z 2013 Solvent-free synthesis of new manganese phosphate-oxalate hybrid solids CrystEngComm 155602

11. Decurtins S, Schmalle H W, Schneuwly P, Zheng L M, Ensling J and Hauser A 1995 Synthesis, Crystal Structure, and Optical and Magnetic Properties of a Novel Two-Dimensional Copper(II) Network Formed Conjointly with $\mu$-Bipyrimidine, $\mu$-Oxalato, and $\mu$ Chloro Ligands Inorg. Chem. 345501

12. Castillo O, Alonso J, García-Couceiro U, Luque A and Román P 2003 A 2D polymer constructed through bridging oxalato and 4,4'-bipyridine ligands: crystal structure and magnetic behavior of $\left[\mathrm{Cu}_{3}(\mu-\mathrm{ox})_{3}\left(\mu-4,4^{\prime}-\right.\right.$ bpy $\left.)_{2}\left(4,4^{\prime}-\text { bpy }\right)_{2}\right]_{n}$ Inorg. Chem. Commun. 6803

13. Glerup J, Goodson P A, Hodgson D J and Michesen K 1995 Magnetic Exchange through Oxalate Bridges: Synthesis and Charachterisation of ( $\mu$-Oxalato)dimetal(II) Complexes of Manganese, Iron, Cobalt, Nickel, Copper, and Zinc Inorg. Chem. 346255

14. Schulz H 1974 Average and Structure of $\mathrm{K}_{2} \mathrm{Mn}\left(\mathrm{C}_{2} \mathrm{O}_{4}\right)_{2}$. $2 \mathrm{H}_{2} \mathrm{O}$ Acta Crystallogr., Sect. B 301318

15. Siddiqui K A, Mehrotra G K and Mrozinski J 2011 Cation-templated 2-D Mn(II)-oxalate framework with an acyclic tetrameric water cluster J. Coord. Chem. 64 2367

16. Li K K, Zhang C and Xu W $2011 \mu$-Oxalato-bis[bis(2,2'bipyridine)-manganese(II)] bis(perchlorate) 2,2'-bipyridine solvate Acta Crystallogr., Sect. E $67 \mathrm{~m} 1443$

17. Feng X, Liu J, Chen J L, Huo S Z, Wang L Y and Ng S W 2014 A unique manganese (II) 2D polymer containing 2,5-di $\left(2^{\prime}, 4^{\prime}\right.$-dicarboxylphenyl) pyridine and oxalate mixed ligands: Structure and magnetic property Inorg. Chem. Commun. $\mathbf{5 0} 42$

18. Yoshitake M, Kubo K, Endo T, Noro S I, Akutagawa T and Nakamura T 2016 Structural Design of Coordination Polymers Based on Manganese and Chromium Ions Bridged by Oxalate Ligands Bull. Chem. Soc. Jpn. 89 354

19. Deguenon D, Bernardinelli G, Tuchagues J P and Castan P 1990 Molecular Crystal Structure and Magnetic Properties of (Croconato)- and (Oxalato)manganese(II) Complexes Inorg. Chem. 293031

20. Abu Youssef M A M, Mautner F A and Vicente R 2008 Two new 2D $\mu$-azido, $\mu$-oxalato manganese(II) complexes. Synthesis, structure and magnetic properties Inorg. Chim. Acta 3612895

21. Mon M, Grancha T, Verdaguer M, Train C, Armentano D and Pardo E 2016 Solvent-Dependent SelfAssembly of an Oxalato-Based Three-Dimensional Magnet Exhibiting a Novel Architecture Inorg. Chem. 55 6845

22. Bain G A and Berry J F 2008 Diamagnetic Corrections and Pascal's Constants J. Chem. Educ. 85532 
23. Duisenberg A J M 1992 Indexing in Single-Crystal Diffractometry with an Obstinate List of Reflections $J$. Appl. Crystallogr. 2592

24. Sheldrick G M 2007 A short history of SHELX Acta Crystallogr., Sect. A 64112

25. Farrugia L J 2012 computer programs WinGX and ORTEP for Windows: an update J. Appl. Crystallogr. 45849

26. Sheldrick G M 2015 Crystal structure refinement with SHELXL Acta Crystallogr., Sect. C 713

27. Brandenburg K 2006 Visual crystal structure information system, Version 3.0 (University of Bonn: Germany)

28. Macrae C F, Edgington P R, McCabe P, Pidcock E, Shields G P, Taylor R, Towler M and Van De Streek J 2006 Mercury: visualization and analysis of crystal structures J. Appl. Crystallogr. 39453

29. Brown I D and Altermatt D 1985 Bond-Valence Parameters Obtained from a Systematic Analysis of the Inorganic Crystal Structure Database Acta Crystallogr., Sect. B 41244

30. Lethbridge Z A D, Congreve A F, Esslemont E, Slawin A M Z and Lightfoot P 2003 Synthesis and structure of three manganese oxalates: $\mathrm{MnC}_{2} \mathrm{O}_{4} \cdot 2 \mathrm{H}_{2} \mathrm{O}$, $\left[\mathrm{C}_{4} \mathrm{H}_{8}\left(\mathrm{NH}_{2}\right)_{2}\right]\left[\mathrm{Mn}_{2}\left(\mathrm{C}_{2} \mathrm{O}_{4}\right)_{3}\right]$ and $\mathrm{Mn}_{2}\left(\mathrm{C}_{2} \mathrm{O}_{4}\right)(\mathrm{OH})_{2} \mathrm{~J}$. Solid State Chem. 172212

31. Pellaux R, Schmalle H W, Decurtins S, Fischer P, Fauth F, Ouladdiaf B and Hauss T 1997 Molecular-Based Magnetism in Bimetallic Two-Dimensional Oxalate-Bridged Networks. An X-ray and Neutron Diffraction Study Phys. B: Condens. Matter 234-236 783

32. García-Couceiro U, Castillo O, Cepeda J, Lanchas M, Luque A, Pérez-Yáñez S, Román P and Vallejo-Sánchez D 2010 Influence of the Synthetic Conditions on the Structural Diversity of Extended Manganese-Oxalato1,2-bis(4-pyridyl)ethylene Systems Inorg. Chem. 49 11346

33. Mancilla N, Caliva V, D'Antonio M C, González-Baró A C and Baran E J 2009 Vibrational spectroscopic investigation of the hydrates of manganese(II) oxalate J. Raman Spectrosc. 40915

34. Sehimi H, Chérif I and Zid M F 2016 Crystal structure and spectroscopic analysis of a new oxalatebridged MnII compound: catena- poly[guanidinium $\left[[\right.$ aquachloridomanganese(II) $]-\mu_{2}$-oxalato- $\kappa^{4} \mathrm{O}^{1}, \mathrm{O}^{2}$ :

$\mathrm{O}^{1}, \mathrm{O}^{2}$ ']monohydrate] Acta Crystallogr., Sect. E 72 724

35. Werner P E, Eriksson L and Westdahl M 1985 TREOR, a semi-exhaustive trial-and-error powder indexing program for all symmetries J. Appl. Crystallogr. 18367

36. Rodriguez C 1990 'FULLPROF' Program, Rietveld Pattern Matching Analysis of Powder Patterns, ILL, Grenoble
37. Zhang $\mathrm{B}$, Zhang $\mathrm{Y}$ and Zhu D 2012 (BEDT-TTF $)_{3} \mathrm{Cu}_{2}\left(\mathrm{C}_{2} \mathrm{O}_{4}\right)_{3}\left(\mathrm{CH}_{3} \mathrm{OH}\right)_{2}$ : an organic inorganic hybrid antiferromagnetic semiconductor Chem. Commun. 48197

38. Duan Z, Zhang Y, Zhang B and Pratt F L 2009 Two homometallic antiferromagnets based on oxalatobridged honeycomb assemblies: $(\mathrm{A})_{2}\left[\mathrm{M}_{2}^{\mathrm{II}}\left(\mathrm{C}_{2} \mathrm{O}_{4}\right)_{3}\right](\mathrm{A}=$ ammonium salt derived from diethylenetriamine; $\mathrm{M}^{\mathrm{II}}=$ $\mathrm{Fe}^{2+}, \mathrm{Co}^{2+}$ ) Inorg. Chem. 482140

39. Chakraborty P, Majumder I, Banu K S, Ghosh B, Kara H, Zangrando E and Das D 2016 Mn(II) complexes of different nuclearity: synthesis, characterization and catecholase-like activity Dalton Trans. 45742

40. Bonner J C and Fisher M E 1964 Magnetism in OneDimensional Systems-The Heisenberg Model for Infinite Spin Phys. Rev. 135 A640

41. Zheng S, Meng X, Zhou Z, Jia L, Yang Y and Shi J 2012 Synthesis, structural analysis and magnetic property of a chiral Mn(II) coordination polymer Inorg. Chem. Commun. 2331

42. De Munno G, Ruiz R, Lloret F, Faus J, Sessoli R and Julve M 1995 Oxalate and 2,2'-Bipyrimidine as Useful Tools in Designing Layered Compounds Inorg. Chem. 34408

43. Keene T D, Zimmermann I, Neels A, Sereda O, Hauser J, Bonin M, Hursthouse M B, Price D J and Decurtins S 2010 Heterocyclic amine directed synthesis of metal(II)oxalates: investigating the magnetic properties of two complete series of chains with $S=5 / 2$ to $S=1 / 2$ Dalton Trans. 394937

44. García-Terán J P, Castillo O, Luque A, García-Couceiro U, Beobide G and Román P 2006 Supramolecular architectures assembled by the interaction of purine nucleobases with metal-oxalato frameworks. Non-covalent stabilization of the $7 \mathrm{H}$-adenine tautomer in the solidstate Dalton Trans. 902

45. Wu W Y, Song Y, Li Y Z and You X Z 2005 One-dimensional structure and long-range antiferromagnetic behaviour of manganese (II) oxalate trihydrate: $\left\{\left[\mathrm{Mn}(\mu-\mathrm{ox})\left(\mathrm{H}_{2} \mathrm{O}\right)_{2}\right] \cdot \mathrm{H}_{2} \mathrm{O}\right\}_{n}$ Inorg. Chem. Commun. 8732

46. Simizu S and Friedberg S A 1988 Quasi-one- and two-dimensional antiferromagnetism in $\alpha-\mathrm{FeC}_{2} \mathrm{O}_{4}$. $2 \mathrm{H}_{2} \mathrm{O}$ and $\alpha-\mathrm{MnC}_{2} \mathrm{O}_{4} \cdot 2 \mathrm{H}_{2} \mathrm{O}$ J. Appl. Phys. 63 3557

47. Curély J, Lloret F and Julve M 1998 Thermodynamics of the two-dimensional Heisenberg classical honeycomb lattice Phys. Rev. B 5811465

48. Negodaev I, De Graaf C and Caballol R 2010 Extraction of magnetic coupling parameters in 2-dimensional magnetic honeycomb layers J. Phys. Chem. A 114 7553 